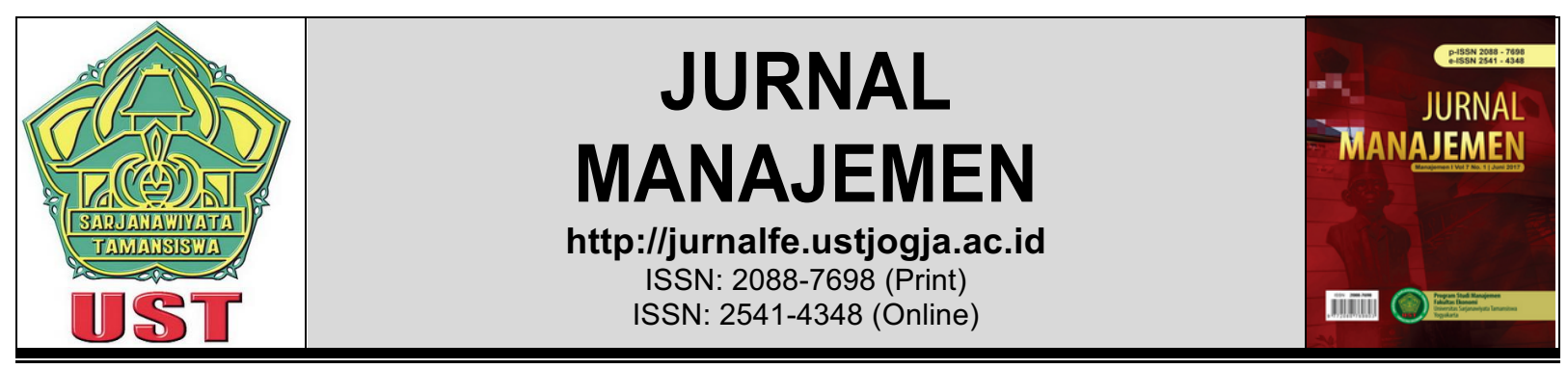

\title{
PENGARUH GAYA KEPEMIMPINAN DAN IKLIM ORGANISASI TERHADAP KEPUASAN KERJA KARYAWAN DI RUMAH SAKIT UMUM DAERAH PRAMBANAN SLEMAN DAERAH ISTIMEWA YOGYAKARTA
}

\author{
Isnanda Zainur Rohman
}

\author{
STIE YKPN
}

Korespondensi: Prof.isnanda@gmail.com

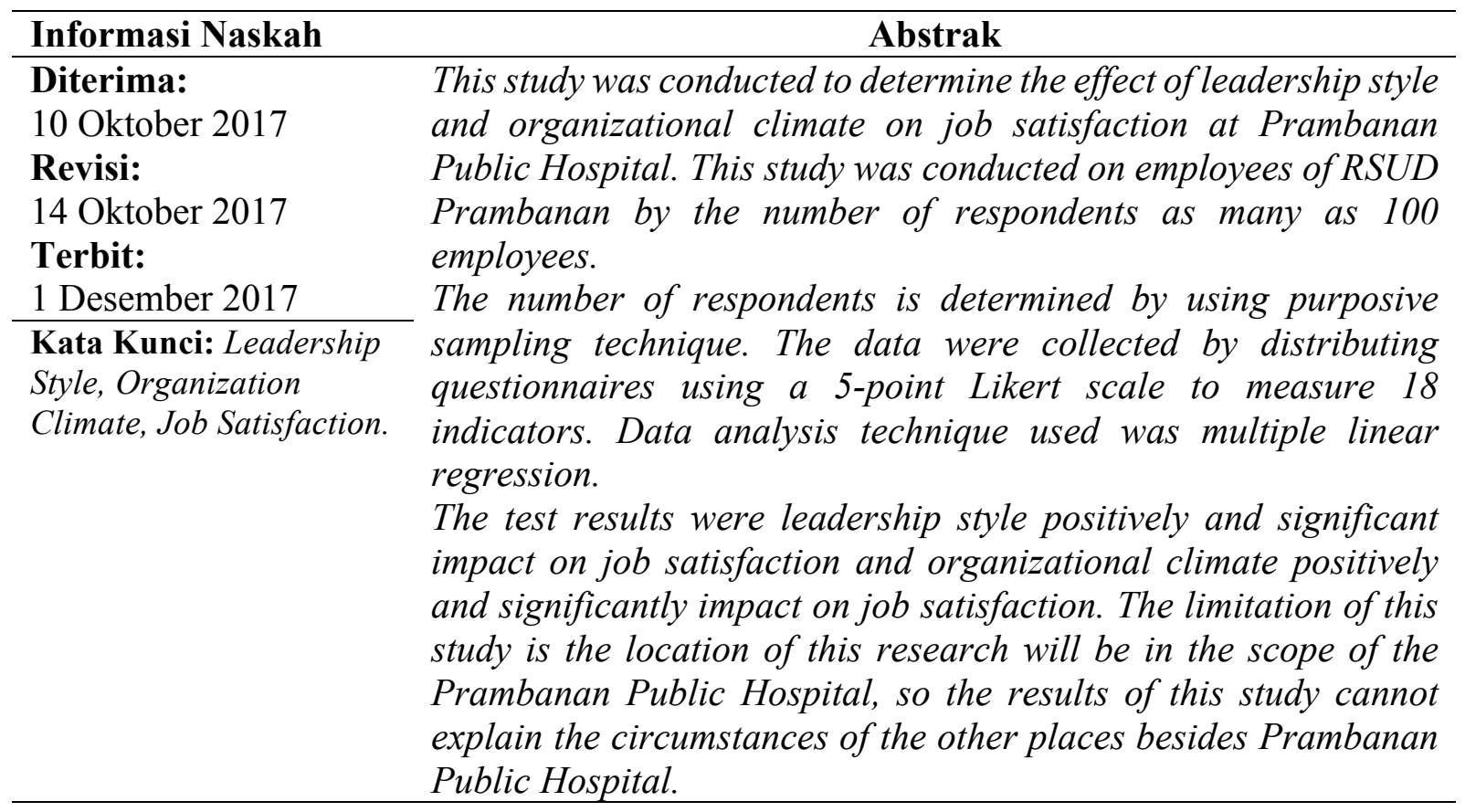

\section{PENDAHULUAN}

Kesehatan memiliki peran yang sangat penting dalam menunjang setiap kegiatan manusia. Menyadari akan hal tersebut, pemerintah sangat serius menangani bidang kesehatan. Dengan memberikan pelayanan kesehatan yang baik, diharapkan muncul generasi penerus bangsa yang sehat dan berkualitas, sehingga mampu membangun peradaban manusia yang lebih baik. Undang-Undang nomor 44 Tahun 2009 tentang rumah sakit telah menetapkan bahwa pemerintah daerah bertanggung jawab menyediakan, menjamin, membina, dan mengawasi penyelenggaraan rumah sakit di daerahnya. Oleh karena itu, penelitian ini diharapkan dapat 
memberi masukan kepada pemerintah daerah khususnya pemerintah daerah kabupaten Sleman dalam melaksanakan tugas dan fungsinya dalam menyelenggarakan dan membina pelayanan kesehatan di RSUD Prambanan.

Dalam melayani pasien, pengelolaan sumber daya manusia merupakan salah satu faktor penentu keberhasilan sebuah rumah sakit. Dengan demikian, pengelolaan karyawan di rumah sakit perlu ditingkatkan. Dengan meningkatnya kinerja karyawan di rumah sakit, diharapkan rumah sakit dapat melayani pasien dengan lebih baik.

Sumber daya manusia merupakan aset penting dalam kehidupan organisasi. Walaupun kualitas teknologi yang digunakan sangat bagus, jika tidak diimbangi dengan kualitas dan kapasitas sumber daya manusia yang memadai, maka efektivitas dan efisiensi kerja dalam organisasi tersebut sulit untuk berjalan dengan baik (Melinda, 2013).

Karyawan, pimpinan, maupun sistem organisasi merupakan elemen dari sumber daya manusia di dalam organisasi. Agar tercipta kepuasan kerja yang tinggi, hubungan yang baik antara para karyawan dengan atasan dan hubungan antara karyawan dengan sesama karyawan harus diperhatikan.

Untuk mendapatkan hasil kerja yang optimal, salah satu faktor yang terpenting adalah kepuasan kerja. Bagi organisasi, suatu pembahasan tentang kepuasan kerja akan menyangkut usaha-usaha untuk meningkatkan efektivitas organisasi. Sesuatu yang tidak menguntungkan baik secara organisasi maupun individual dapat terjadi jika karyawan merasa tidak puas dalam bekerja (Sutrisno, 2014).

Perilaku yang agresif atau sebaliknya akan menunjukkan sikap menarik diri dari kontak dengan lingkungan sosialnya akan timbul jika karyawan tidak puas dalam bekerja. Karyawan akan melakukan sabotase, membuat kesalahan dengan disengaja, menentang atasan dan melakukan pemogokan kerja. Sedangkan jika karyawan merasa puas dalam bekerja, produktivitas atau hasil kerja karyawan juga akan meningkat. Kepuasan kerja yang tinggi akan berdampak pada prestasi kerja dan kinerja yang baik.

\section{KAJIAN PUSTAKA DAN HIPOTESIS}

Kepuasan kerja karyawan merupakan hal penting yang perlu diperhatikan dalam hubungannya dengan produktivitas kerja karyawan (Sutrisno, 2014). Brahmasari dan Suprayetno (2008) mengemukakan bahwa kepuasan kerja merupakan penilaian perasaan atas sikap karyawan terhadap pekerjaannya dan hubungannya dengan lingkungan kerja, kompensasi, jenis pekerjaan, hubungan antar teman kerja dan sebagainya. Irsan (2008) menyatakan bahwa banyak variabel yang mempengaruhi kepuasan kerja, yaitu motivasi kerja, disain pekerjaan, karakteristik karyawan, struktur organisasi, iklim organisasi, dan perilaku pemimpin.

Mangkunegara (2009) menyatakan bahwa kepuasan kerja adalah perasaan dari seseorang yang menyenangkan atau tidak menyenangkan yang berhubungan dengan pekerjaannya atau dirinya sendiri. Kepuasan kerja merupakan sebuah sikap karyawan secara emosional yang menyenangkan dan mencintai pekerjaannya dengan sepenuh hati (Han et al., 2012).

Handoko (2014) menyatakan bahwa kepuasan kerja adalah keadaan emosional yang menyenangkan atau tidak menyenangkan dimana para karyawan memandang pekerjaan mereka. Siagian (2011) berpendapat bahwa kepuasan kerja merupakan cara pandang seseorang baik yang bersifat positif maupun negatif tentang pekerjaannya. Zainal dkk. (2014) menyatakan bahwa kepuasan kerja adalah penilaian dari pekerja tentang seberapa jauh pekerjaannya secara keseluruhan memuaskan kebutuhannya. Kusmaningtyas (2013) menyatakan bahwa kepuasan 
kerja merupakan suatu refleksi terhadap terpenuhinya kebutuhan dan keinginan individu yang didapat dari pekerjaannya.

Pemilihan variabel independen dalam penelitian ini didasarkan pada: 1) Beberapa nilai yang mempengaruhi gaya kepemimpinan yang dimiliki oleh pemimpin pada karyawan, hal ini dipengaruhi dari bagaimana pemimpin dapat memberikan dukungan terhadap karyawan, bagaimana toleransi pemimpin terhadap risiko-risiko yang ada, bagaimana kriteria pengupahan karyawan, dan bagaimana pembagian beban kerja yang dilakukan oleh pemimpin, hal tersebut nantinya dapat mempengaruhi pada puas atau tidak puasnya karyawan terhadap pekerjaannya. 2) Iklim organisasi, penilaian-penilaian tentang perusahaannya dapat dilakukan oleh karyawan dan membentuk persepsi dalam dirinya, hal tersebut dilakukan dengan suatu proses interaksi yang berkaitan dengan kondisi organisasi tersebut dan kesesuaian terhadap dirinya.

Peran pemimpin dalam organisasi merupakan salah satu faktor kepuasan kerja karyawan yang paling penting. Pemimpin harus mampu menentukan tujuan, merencanakan, mengorganisasikan, menggerakkan serta mengendalikan seluruh sumber daya yang dimiliki. Kepemimpinan adalah hal utama dalam manajemen yang memegang peranan penting dan strategis untuk kelangsungan hidup suatu perusahaan. Kepemimpinan yang efektif bisa membantu organisasi untuk dapat bertahan dalam situasi ketidakpastian di masa yang akan datang (Desianty, 2005).

Gaya kepemimpinan merupakan srategi pemimpin dalam mengarahkan karyawan baik secara langsung atau tidak langsung untuk melakukan pekerjaannya (Ruvendi, 2005). Zainal dkk. (2014) mengemukakan bahwa suatu proses yang mempengaruhi dan memberikan contoh dari pemimpin kepada bawahannya untuk mencapai tujuan organisasi disebut dengan kepemimpinan. Memerintah bawahan dengan gaya kepemimpinan masing-masing adalah wewenang dari pemimpin, dan bawahan akan menerima perintah dari pimpinannya dengan sudut pandang yang berbeda-beda.

Gaya kepemimpinan memiliki peranan penting, karena pemimpin merupakan fungsi manajemen yang dapat mempengaruhi karyawan dalam bekerja untuk dapat mencapai tujuan organisasi Skansi (2000). Penelitian yang dilakukan Rahman et al. (2012) mengemukakan setiap orang akan mengambil gaya kepemimpinan yang berbeda-beda sesuai dengan situasi yang dihadapi mereka pada waktu itu. Cheung dan Fai Chan (2008) juga menyatakan bahwa gaya kepemimpinan pada organisasi dimana setiap pemimpin pada masing-masing organisasi memiliki cara dan gaya yang berbeda-beda.

Lumbanraja (2009) menyatakan penekanan kelompok, dukungan terhadap karyawan, toleransi terhadap risiko, dan kriteria pengupahan akan dipengaruhi dari gaya kepemimpinan yang dimiliki oleh seorang pemimpin. Gaya kepemimpinan seorang pemimpin akan mempengaruhi kondisi kerja, motivasi dan kepuasan kerja karyawan yang dapat mengakibatkan peningkatan kinerja dan sebaliknya dapat menyebabkan penurunan kinerja, jika penerapannya tidak disesuaikan dengan kondisi perilaku kerja dari para anggota organisasi.

Robbins dan Judge (2015) pemimpin adalah orang yang mempunyai tugas untuk mengarahkan dan membimbing bawahan dan mampu memperoleh dukungan bawahan sehingga dapat menggerakkan bawahan ke arah pencapaian tujuan organisasi. Kepemimpinan adalah kemampuan untuk mempengaruhi suatu kelompok menuju pencapaian sebuah visi atau tujuan yang ditetapkan. Xenikou (2006) menyatakan hasil yang baik yang ditunjukkan karyawan dan organisasi di pengaruhi oleh bagaimana gaya kepemimpinan yang dimiliki oleh pemimpin tersebut. Zainal dkk. (2014) menyatakan bahwa gaya kepemimpinan merupakan sekumpulan ciri yang digunakan para pemimpin dalam mempengaruhi bawahan agar sasaran organisasi 
tercapai. Riyanti (2012) menyatakan bahwa gaya kepemimpinan adalah suatu cara yang digunakan seorang pemimpin dalam mempengaruhi perilaku orang lain.

Setiap gaya kepemimpinan memiliki keunggulan dan kelemahan. Setiap pemimpin menggunakan gaya kepemimpinannya sesuai kemampuan, kepribadian dan situasi dalam pekerjaan (Heidjrachman dan Husnan, 2002). Pemimpin juga harus mampu menjadi panutan yang lebih baik bagi bawahannya dalam organisasi. Berbagai persoalan yang timbul pada perusahaan pemimpin diharapkan mampu menghadapinya dengan baik, baik itu persoalan tentang perusahaan atau karyawan, agar terciptanya hubungan yang baik antara karyawan dan pemimpinnya. Tampubolon (2007) menyatakan bahwa faktor gaya kepemimpinan memberikan kontribusi yang cukup besar terhadap peningkatan kinerja pegawai pada organisasi. Kepuasan kerja bagi karyawan akan tercipta dengan baik dari pemimpin yang baik dalam memimpin karyawannya (Riyanti, 2012).

Faktor lain yang mempengaruhi tingkat kepuasan kerja selain gaya kepemimpinan adalah iklim organisasi. Iklim organisasi dapat menentukan bagamana suatu interaksi di dalam organisasi untuk dapat mencapai tujuan perusahaan. Karyawan akan melakukan penilaianpenilaian terhadap perusahaan dan membentuk presepsi tentang iklim organisasi di perusahaan tersebut. Iklim organisasi adalah persepsi individu terhadap pekerjaan yang dirasakan (James et al., 2008). Iklim organisasi adalah hubungan antar individu yang dapat mempengaruhi perilakunya sehingga dapat meningkatkan produktivitas kerja (Sukarman, 2012).

Iklim organisasi penting untuk diciptakan karena merupakan persepsi seseorang tentang apa yang diberikan oleh organisasi dan dijadikan dasar bagi penentu tingkah laku anggota selanjutnya (Unika dan Kartika, 2010). Iklim organisasi mempunyai hubungan yang positif terhadap kepuasan kerja (Kangis et al., 2000). Sari (2009) mengemukakan bahwa iklim organisasi mempengaruhi kepuasan kerja dengan membuktikan bahwa kepuasan kerja diperoleh dari sistem sosial yang dipengaruhi oleh lingkungan internal dan eksternal. Susanty (2012) menyatakan bahwa iklim organisasi di setiap organisasi itu berbeda-beda, iklim organisasi yang berbeda-beda tersebut dapat mempengaruhi perilaku sumberdaya manusia di organisasi tersebut.

Mastaneh (2011) mengatakan iklim organisasi merupakan atribut yang dapat dirasakan dalam sebuah organisasi tertentu. Wirawan (2009) menyatakan bahwa iklim organisasi adalah cara anggota organisasi (secara individual atau kelompok) tetap berhubungan dengan organisasi. Cheng (2010) menyatakan Iklim organisasi adalah konsekuensi dari interaksi antara individu dalam suatu organisasi dan lingkungan eksternal mereka. Zohar dan Luria (2005) menyatakan bahwa iklim organisasi dapat didefinisikan sebagai pembagian persepsi dari apa yang dirasakan dan apa yang didapat di dalam organisasi. Iklim organisasi merupakan keseluruhan pernyataan yang diyakini oleh karyawan atau anggota organisasi terhadap pekerjaan dan kontribusinya pada organisasi (Arvidsson et al., 2006). Faktor-faktor yang mempengaruhi iklim organisasi meliputi kepemimpinan, motivasi, komunikasi, proses pengaruh interaksi, pembuatan keputusan, penentuan tujuan dan kontrol (Wibisono, 2011).

Iklim organisasi yang baik menimbulkan kenyamanan, saling menghormati dan kebersamaan dalam bekerja (Imam dan Erika, 2013). Kepuasan kerja karyawan akan meningkat jika iklim dalam organisasi tersebut baik dan sehat, sehingga karyawan akan merasa nyaman dalam menyelesaikan tugasnya (Khaeron, 2009). Seseorang akan merasa puas dan memiliki kemauan yang besar untuk menyelesaikan suatu pekerjaan yang menjadi kewajibannya dan bahkan melakukan tugas di luar perannya jika berada pada iklim organisasi yang baik (Intifada, 2013). Iklim organisasi juga berpengaruh langsung terhadap sikap kerja dan meningkatkan 
prestasi kerja karyawan (Muhammad, 2006).

Penelitian yang dilakukan oleh Ahmad et al. (2013) menunjukkan bahwa gaya kepemimpinan memiliki pengaruh yang positif terhadap kepuasan kerja perawat. Arzi dan Farahbod (2014) dalam penelitiannya juga mendapatkan hasil yang sama dimana gaya kepemimpinan berpengaruh positif terhadap kepuasan kerja karyawan, studi ini dilakukan pada industri hotel di Iran. Intifada (2013) dengan hasil penelitian yang menunjukkan bahwa terdapat pengaruh signifikan antara gaya kepemimpinan terhadap kepuasan kerja.

Berdasarkan pembahasan di atas, maka dapat dirumuskan pertanyaan penelitian yaitu apakah gaya kepemimpinan berpengaruh terhadap kepuasan kerja dan apakah iklim organisasi berpengaruh terhadap kepuasan kerja. Penelitian ini bertujuan untuk mengetahui pengaruh gaya kepemimpinan terhadap kepuasan kerja dan mengetahui pengaruh iklim organisasi terhadap kepuasan kerja.

Safitri (2012) dalam penelitiannya juga menemukan hasil yang menunjukkan pengaruh dari gaya kepemimpinan terhadap kepuasan kerja. Plangiten (2013) juga menemukan hasil penelitian yang sama bahwa gaya kepemimpinan berpengaruh positif terhadap kepuasan kerja. Maqsood (2013) dalam penelitiannya juga menemukan hasil serupa bahwa gaya kepemimpinan memiliki hubungan yang positif terhadap kepuasan kerja.

\section{H1: Gaya kepemimpinan berpengaruh positif dan signifikan terhadap kepuasan kerja} karyawan.

Kustianto dan Iskhak (2015) mengemukakan bahwa iklim organisasi memiliki pengaruh positif dan signifikan terhadap kepuasan kerja karyawan. Faozi (2014) mengemukakan bahwa iklim organisasi memiliki pengaruh yang positif terhadap kepuasan kerja guru. Kusmaningtyas (2013) dalam penelitiannya juga menemukan iklim organisasi berpengaruh positif terhadap kepuasan kerja karyawan. Mei Teh (2014) dalam penelitiannya juga menemukan iklim organisasi memiliki pengaruh terhadap kepuasan kerja karyawan. Johannes (2014) menemukan hasil yang sama dalam penelitiannya bahwa iklim organisasi memiliki pengaruh yang positif terhadap kepuasan kerja, studi ini dilakukan terhadap 124 karyawan yang bekerja pada PT. Trimitra Lestari di Jambi.

\section{H2: Iklim organisasi berpengaruh positif dan signifikan terhadap kepuasan kerja karyawan}

\section{METODE PENELITIAN}

Pendekatan dalam penelitian ini adalah pendekatan kuantitatif. Penelitian ini menggunakan desain penelitian asosiatif, yaitu menganalisis pengaruh gaya kepemimpinan dan iklim organisasi terhadap kepuasan kerja karyawan di RSUD Prambanan. Berdasarkan teori dan hasil penelitian sebelumnya dapat disajikan kerangka konseptual seperti berikut.

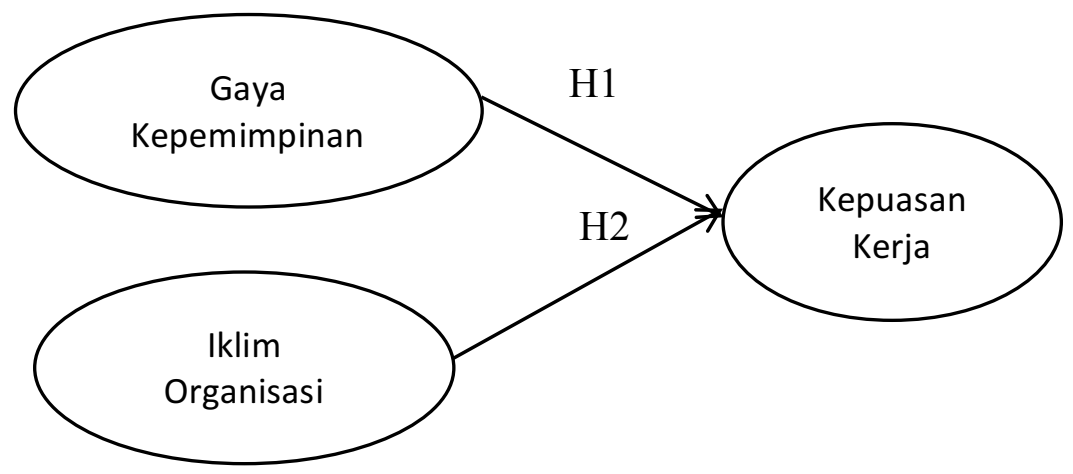


Penelitian ini menggunakan data primer. Responden dalam penelitian ini adalah karyawan RSUD Prambanan sebanyak 100 orang. Metode pengambilan sampel yang digunakan adalah purposive sampling. Kuesioner yang disebar berupa daftar pernyataan tertulis kepada responden mengenai pengaruh gaya kepemimpinan, iklim organisasi dan kepuasan kerja. Teknik pengukuran nilai yang digunakan dalam penelitian ini adalah skala likert. Dengan skala likert, maka variabel yang akan diukur dijabarkan dengan indikator variabel (Sugiyono, 2010). Instrumen dalam penelitian ini mengadopsi instrumen penelitian yang telah dikembangkan oleh peneliti sebelumnya yaitu semua jawaban dari pertanyaan akan diukur dalam lima skor dengan menggunakan skala ordinal 5 poin Likert, mulai dari sangat setuju (poin 5) sampai sangat tidak setuju (poin 1).

Analisis regresi linear berganda dipergunakan untuk mengetahui pengaruh dari variabel independen terhadap variabel dependen. Persamaan regresi linear berganda dalam penelitian ini dirumuskan sebagai berikut: $\hat{\mathrm{Y}}=\mathrm{a}+\mathrm{b} 1 \mathrm{x} 1+\mathrm{b} 2 \mathrm{x} 2+\varepsilon$

Keterangan: $\hat{\mathrm{Y}}=$ Kepuasan kerja a $=$ Konstanta $\mathrm{X} 1=$ Gaya kepemimpinan $\mathrm{X} 2=$ Iklim organisasi b1 $=$ Koefisien regresi dari X1 b2 $=$ Koefisien regresi dari X2 $\varepsilon=$ error

\section{HASIL DAN PEMBAHASAN}

Tabel 1 menunjukkan bahwa hasil persentase jumlah responden yang berjenis kelamin laki-laki sebanyak 44\%, sedangkan persentase jumlah responden yang berjenis kelamin perempuan sebesar 56\%. Jumlah total responden pada penelitian ini adalah 100 orang.

Tabel 1

Karakteristik Responden Berdasarkan Jenis Kelamin

\begin{tabular}{llll|}
\hline No. & Jenis Kelamin & Jumlah & Persentase \\
\hline $\mathbf{1}$ & Laki - laki & 44 & $44 \%$ \\
$\mathbf{2}$ & Perempuan & 56 & $56 \%$ \\
Jumlah & 100 & $100 \%$ \\
\hline
\end{tabular}

Tabel 2 menunjukkan responden berumur antara 21-30 tahun berjumlah 40 orang, responden berumur 31-40 tahun berjumlah 35 orang, responden berumur 41-50 tahun berjumlah 20 orang, dan responden berumur 51-60 tahun berjumlah 5 orang.

Tabel 2

Karakteristik Responden Berdasarkan Kategori Umur

\begin{tabular}{llll|}
\hline & & & \\
\hline $\mathbf{1}$ & $21-30$ & 40 & $40 \%$ \\
$\mathbf{2}$ & $31-40$ & 35 & $35 \%$ \\
$\mathbf{3}$ & $41-50$ & 20 & $20 \%$ \\
$\mathbf{4}$ & $51-60$ & 5 & $5 \%$ \\
Jumlah & 100 & $100 \%$ \\
\hline
\end{tabular}

Tabel 3 menunjukkan responden dengan tingkat pendidikan SMA berjumlah 9 orang, responden dengan tingkat pendidikan D3 berjumlah 71 orang, responden dengan tingkat pendidikan S1 berjumlah 20 orang. 
Tabel 4

Karakteristik Responden Berdasarkan Tingkat Pendidikan

\begin{tabular}{|llll|}
\hline No. & Tingkat Pendidikan & Jumlah & Persentase \\
\hline $\mathbf{1}$ & SMA & 9 & $9 \%$ \\
\hline $\mathbf{2}$ & D3 & 71 & $71 \%$ \\
\hline $\mathbf{3}$ & S1 & 20 & $20 \%$ \\
\hline Jumlah & 100 & $100 \%$ \\
\hline
\end{tabular}

Tabel 6 menunjukkan nilai dari masing-masing indikator variabel memiliki nilai loading factor lebih besar dari 0,5. Analisis faktor dinyatakan valid jika memenuhi syarat loading factor lebih besar dari 0,5 (Ghozali, 2011)

Tabel 6

Hasil Uji Validitas

\begin{tabular}{|c|c|c|c|c|}
\hline No. & Variabel & Indikator & Loading Factor & Keterangan \\
\hline \multirow[t]{6}{*}{1.} & Kepuasan Kerja (Y) & Y1 & 0,754 & Valid \\
\hline & & Y2 & 0,906 & Valid \\
\hline & & Y3 & 0,876 & Valid \\
\hline & & Y4 & 0,888 & Valid \\
\hline & & Y5 & 0,754 & Valid \\
\hline & & Y6 & 0,904 & Valid \\
\hline \multirow[t]{6}{*}{2.} & Gaya Kepemimpinan (X1) & $\mathrm{X} 1.1$ & 0,967 & Valid \\
\hline & & $\mathrm{X} 1.2$ & 0,878 & Valid \\
\hline & & $\mathrm{X} 1.3$ & 0,865 & Valid \\
\hline & & $\mathrm{X} 1.4$ & 0,901 & Valid \\
\hline & & $\mathrm{X} 1.5$ & 0,802 & Valid \\
\hline & & $\mathrm{X} 1.6$ & 0,770 & Valid \\
\hline \multirow[t]{6}{*}{3.} & Iklim Organisasi (X2) & $\mathrm{X} 2.1$ & 0,907 & Valid \\
\hline & & $\mathrm{X} 2.2$ & 0,953 & Valid \\
\hline & & $\mathrm{X} 2.3$ & 0,856 & Valid \\
\hline & & $\mathrm{X} 2.4$ & 0,765 & Valid \\
\hline & & $\mathrm{X} 2.5$ & 0,886 & Valid \\
\hline & & $X 2.6$ & 0,876 & Valid \\
\hline
\end{tabular}

Tabel 7 menunjukkan masing-masing nilai Cronbach's Alpha pada tiap variabel lebih besar dari 0,60 (Cronbach's Alpha >0,60). Hal tersebut menunjukkan bahwa semua instrumen reliabel sehingga dapat digunakan untuk melakukan penelitian (Sekaran, 2006).

Tabel 7

Hasil Uji Realibilitas

\begin{tabular}{|llll|}
\hline No. & Variabel & Cronbach's Alpha & Keterangan \\
\hline 1. & Kepuasan Kerja & 0,776 & Reliable \\
\hline 2. & Gaya Kepemimpinan & 0,856 & Reliable \\
\hline 3. & Iklim Organisasi & 0,875 & Reliable \\
\hline
\end{tabular}

Sebelum dilakukan uji regresi linier berganda, peneliti terlebih dahulu melakukan uji asumsi klasik. Hasil dari uji asumsi klasik dalam penelitian ini menunjukkan bahwa data 
terdistribusi normal, tidak terdapat multikolinieritas, tidak terjadi homogenitas, dan tidak terdapat autokorelasi.

Pengaruh dari variabel dependen terhadap variabel independen ditunjukkan dari hasil persamaan regresi linear berganda pada Tabel 8 . Tabel tersebut menunjukkan bahwa gaya kepemimpinan berpengaruh positif dan signifikan terhadap kepuasan kerja karyawan RSUD Prambanan yang ditunjukkan dengan nilai probalitiy $0,021(\mathrm{p}<0,05)$. Tabel tersebut juga menunjukkan bahwa iklim organisasi berpengaruh positif dan signifikan terhadap kepuasan kerja karyawan RSUD Prambanan yang ditunjukkan dengan nilai probability $0,001(\mathrm{p}<0,05)$.

Tabel 8

Hasil Uji Regresi

\begin{tabular}{|lccc|}
\hline \multicolumn{1}{|c|}{ Hipotesis } & \multicolumn{1}{c|}{$\begin{array}{c}\text { Standardized } \\
\text { Regression } \\
\text { Weights }\end{array}$} & Probability & Keterangan \\
\hline $\begin{array}{l}\text { H1: Gaya kepemimpinan berpengaruh } \\
\text { positif terhadap kepuasan kerja karyawan } \\
\text { RSUD Prambanan }\end{array}$ & 0,104 & 0,036 & $\begin{array}{l}\text { Hipotesis } \\
\text { didukung }\end{array}$ \\
\hline $\begin{array}{l}\text { H2: Iklim organisasi berpengaruh positif } \\
\text { terhadap kepuasan kerja karyawan RSUD } \\
\text { Prambanan }\end{array}$ & 0,644 & 0,001 & Hipotesis \\
didukung
\end{tabular}

Penelitian Ahmad et al. (2013) juga mendapatkan hasil yang sejalan dengan hasil dari penelitian ini bahwa gaya kepemimpinan berengaruh positif dan signifikan terhadap kepuasan kerja. Intifada (2013) dengan hasil penelitiannya menunjukkan bahwa terdapat pengaruh yang positif dan signifikan antara gaya kepemimpinan terhadap kepuasan kerja. Plangiten (2013) juga mengungkapkan hasil penelitian yang menunjukkan bahwa gaya kepemimpinan berpengaruh positif dan signifikan terhadap kepuasan kerja karyawan. Penelitian yang juga dilakukan oleh Safitri dkk. (2012) mengenai adanya pengaruh yang positif dan signifikan antara gaya kepemimpinan terhadap kepuasan kerja.

Hasil penelitian ini menyatakan bahwa variabel iklim organisasi memiliki pengaruh yang positif dan signifikan terhadap variabel kepuasan kerja, ini berarti bahwa thitung yang lebih besar dari pada ttabel, memiliki arti iklim organisasi memiliki pengaruh yang positif dan signifikan terhadap kepuasan kerja. Iklim organisasi memiliki hubungan yang searah dengan kepuasan kerja, jadi jika iklim organisasi meningkat maka tingkat kepuasan kerja juga akan meningkat.

Penelitian ini mendukung hipotesis kedua dari penelitian yang dilakukan oleh Kusmaningtyas (2013) tentang bagaimana iklim organisasi dan kepemimpinan mempengaruhi kepuasan kerja karyawan yang memiliki pengaruh secara positif dan signifikan. Kustianto dan Iskhak (2015) juga menemukan hasil bahwa iklim organisasi berpengaruh positif dan signifikan terhadap kepuasan kerja karyawan. Faozi (2014) menemukan hasil penelitian iklim organisasi memiliki pengaruh yang positif dan signifikan terhadap kepuasan kerja karyawan. Penelitian yang juga dilakukan oleh Bhaesajsanguan (2010) bahwa iklim organisasi memiliki hubungan positif dan signifikan terhadap kepuasan kerja karyawan. 


\section{PENUTUP}

Dari hasil analisis dan hasil pembahasan, maka dapat ditarik beberapa kesimpulan yaitu gaya kepemimpinan berpengaruh positif dan signifikan terhadap kepuasan kerja karyawan di RSUD Prambanan. Artinya, semakin baik gaya kepemimpinan di dalam sebuah organisasi, maka kepuasan kerja karyawan akan meningkat. Iklim organisasi memiliki pengaruh yang positif dan signifikan terhadap kepuasan kerja karyawan di RSUD Prambanan. Dengan demikian, jika iklim organisasi di dalam sebuah organisasi semakin baik, maka kepuasan kerja yang dirasakan oleh karyawan akan semakin meningkat.

Dari hasil penelitian dan simpulan, maka saran yang dapat diberikan penulis adalah pimpinan RSUD Prambanan perlu mempertahankan gaya kepemimpinannya dan bahkan meningkatkannya supaya tercipta kepuasan kerja karyawan yang semakin meningkat. Pimpinan RSUD Prambanan perlu mempertahankan dan meningkatkan sikap saling percaya antara karyawan dengan pimpinan supaya tercipta hubungan yang harmonis antara pimpinan dengan karyawan. Dengan terciptanya kepuasan kerja di lingkungan RSUD Prambanan, kinerja karyawan yang baik akan dirasakan oleh masyarakat, sehingga pelayanan kesehatan di RSUD Prambanan semakin baik

\section{REFERENSI}

Ahmad, Abd Rahman., Mohd Nazir Mohd Adi., Haris Md Noor., Abdul Ghafar Abdul Rahman., and Tan Yushuang. 2013. The Influence of Leadership Style on Job Satisfaction among Nurses. Asian Social Science Journal, 9. ( 9):1911-1925.

Arvidsson, M., Johansson, CR, Ek A., dan Akselsson, R. 2006. Organizational Climate in Air Traffic Control: Innovative Preparedness for Implementation of New Technology and Organizational Development in a Rule Governed Organization. Appl. Ergon, 37(2):11929.

Bhaesajsanguan, Sanguansak. 2010. The Relationships among Organizational Climate, Job Satisfaction and Organizational Commitment in the Thai Telecommunication Industry. E-Leader Singapore Journal, 10: -15 .

Brahmasari, IA., dan Agus Suprayetno. 2008. Pengaruh Motivasi Kerja, Kepemimpinan dan Budaya Organisasi Terhadap Kepuasan Kerja Karyawan Serta Dampaknya Pada Kinerja Perusahaan (Studi Kasus Pada PT. Pei Hal Internasional Wiratama Indonesia). Jurnal Manajemen dan Kewirausahaan, 10(2):124-135.

Cheng, C.Y. 2010. Organizational Climate, Organizational Commitment and Intention to leave amongst hospital nurses in Taiwan. Journal of Clinical Nursing, (19):1635 - 1644.

Cheung, Chau Kiu., and Fai Chan. 2008. Benefits of Hongkong Chinese CEOs' Confucian and Daoist Leadership Styles. Leadership and Organization Development Journal, 29(6):474503.

Desianty, Sovyia. 2005. Pengaruh Gaya Kepemimpinan Terhadap Komitmen Organisasi Pada PT. Pos Indonesia Semarang. Jurnal Studi Manajemen dan Organisasi, 2(1):69-84.

Faozi, Mohamad. 2014. Pengaruh Komitmen Organisasi, Kompensasi, Budaya Kerja, Motivasi dan Iklim Organisasi terhadap Kepuasan Kerja Guru SMP Negeri dan Swasta Di Kecamatan Tarub Kabupaten Tegal. Jurnal Magister Manajemen UDINUS Semarang.

Flippo, Edwin B. 1993. Manajemen Personalia. Edisi 6. Erlangga. Jakarta.

Han, Sia Tjun., Agustinus Nugroho, Endo W. Kartika., dan Thomas S. 2012. Komitmen Afektif Dalam Organisasi yang Dipengaruhi Perceived Organizational Supportdan Kepuasan Kerja. Jurnal Manajemen dan Kewirausahaan, 14(2):109-117. 
Handoko, T. Hani. 2014. Manajemen Personalia dan Sumber Daya Manusia. Edisi Kedua. Yogyakarta: BPFE.

Heidjrachman, Ramupandoju dan Suad Husnan.2002. Manajemen Personalia. Edisi Keempat. Yogyakarta : BPFE.

Intifada, Khoirina Yuniarti. 2013. Analisis Pengaruh Gaya Kepemimpinan dan Iklim Organisasi terhadap Peningkatan Kinerja Guru melalui Kepuasan Kerja Guru pada SMA Negeri 3 Jember. Skripsi. Fakultas Ekonomi Universitas Jember.

Imam, Aryansah dan Erika Setyanti Kusumaputri. 2013. Iklim Organisasi dan Kualitas Kehidupan Kerja Karyawan. Jurnal Psikologi Indonesia, X(1)

Irsan. 2008. Pengaruh Kepemimpinan, Disain Pekerjaan, dan Iklim Organisasi Terhadap Kepuasan Kerja Tenaga Penunjang Akademik di Universitas Negeri Medan. Jurnal Manajemen Pendidikan, :363-376.

James, LR., Choi, CC., Ko, C-HE., McNeil, PK., Minton, MK., Wright, MA dan KimK. 2008. Organizational and Psychological Climate: A Review of Theory and Research. Eur Jurnal Work Organ Psycho,17:5-32.

Johannes, Edward dan Muchid Rofii.2014. Pengaruh Kompensasi dan Iklim Organisasi Terhadap Turnover Intension dengan Kepuasan Kerja sebagai Variabel Intervening. Jurnal Dinamika Manajemen, 2(2):141-152.

Kaiser, R.B., Hoogan, R \& Craig, S.B. 2008. Leadership and the Fate of Organizations. American Psychologist Journal, 63(2):96-110.

Kangis, P., Gordon dan Williams S. 2000. Oragnizational Climate and Corporate Performance. Journal of Management Decision, 38(8):531-540.

Khaeron, M. 2009. Motivasi Pengembangan Karir dan Iklim Organisasi Pengaruhnya Terhadap Kepuasan Kerja Karyawan. Analisis Manajemen. 4(1):29-39.

Kusmaningtyas, Amiartuti. 2013. Pengaruh Iklim Organisasi dan Kepemimpinan Terhadap Kepuasan Kerja Karyawan PT. Persada Jaya Indonesia di Kabupaten Sidoarjo. Jurnal Ekonomi dan Manajemen Bisnis, 4(1):107120.

Kustianto, Fery dan Ahmad Abidin Iskhak. 2015. Pengaruh Iklim Organisasi Terhadap Komitmen Karyawan dengan Kepuasan Kerja sebagai Variabel Intervening pada PT. Garam (PERSERO). Jurnal Ilmu Manajemen MAGISTRA, 1(1):42-55.

Lumbanraja, Prihatin. 2009. Pengaruh Karakteristik Individu, Gaya Kepemimpinan dan Budaya Organisasi terhadap Kepuasan Kerja dan Komitmen Organisasi. Jurnal Aplikasi Manajemen, 7(2):450-468.

Mangkunegara, A.A Anwar Prabu. 2009. Psikologi Industri dan Organisasi. Jakarta: Universitas Indonesia.

Maqsood, Sumbal. 2013. Manager's Leadership Style and Employee's Job Satisfaction. Human and Social Science Research, 1(2):139-144.

Mastaneh, G. 2011. Study of Relationship between Organizational Climate and Commitment staff in Sosangerd Azad University. Australian Journal of Basic and Applied Sciences, $5(12)$

Mei Teh, Goi. 2014. Impact of Organizational Climate on Intentions to Leave and Job Satisfaction. World Journal of Management, 5(2):14 - 24.

Melinda, Tri Febrina, Kamaludin., dan Nasution. 2013. Analisis Pengaruh Iklim Organisasi dan Promosi Jabatan terhadap Kepuasan Kerja Karyawan PT. Bank Bengkulu Cabang Utama. Jurnal Ilmiah Manajemen, Vol. 13 No. 1. hal. 28-36.

Muhammad, Idrus. 2006. Implikasi Iklim Organisasi Terhadap Kepuasan Kerja dan Kualitas 
Kehidupan Kerja Karyawan. Jurnal Psikologi Universitas Diponegoro, Vol. 3. No. 1.

Plangiten, Pegi. 2013. Gaya Kepemimpinan dan Lingkungan Kerja Pengaruhnya Terhadap Kepuasan Kerja Karyawan pada PT. Pos Indonesia (PERSERO) Manado. Jurnal EMBA, 1(4):2155-2166.

Rehman, Saad-ur., Muhammad Mansoor and Rafi Ullah Bilal. 2012. The Impact of Leadership Styles on Job Satisfaction at Work Place. Arabian Journal of Business and Management Review (OMAN Chapter), 1(2):26-42.

Riyanti, Dewi. 2012. Pengaruh Gaya Kepemimpinan dan Lingkungan Kerja terhadap Kepuasan Kerja Karyawan AJB Syariah Bumiputera Cirebon. Skripsi. Fakultas Syariah dan Ekonomi Islam, Cirebon.

Robbins, Stephen P. dan Timothy A. Judge. 2015. Perilaku Organisasi, Edisi 16. Jakarta: Salemba Empat.

Sekaran, U. 2006. Research Method Business. Hermitage Publishing Services

Tampubolon, Biatna Dulbert. 2007. Analisis Gaya Kepemimpinan dan Faktor Etos Kerja Terhadap Kinerja Pegawai Pada Organisasi yang Telah menerapkan SNI 19-9001-2001. Jurnal Standardisasi, 9(3):106-115.

Teman, Koesmono. 2005. Pengaruh Budaya Organisasi Terhadap Motivasi dan Kepuasan Kerja Serta Kinerja Karyawan Pada Sub Sektor Industri Pengolahan Kayu Skala Menengah di Jawa Timur. Jurnal Manajemen dan Kewirausahaan, 7(2):171-188.

Safitri, Husnaina Mailisa., Amri dan M. Shabri. 2012. Pengaruh Gaya Kepemimpinan, Kerjasama Tim, dan Gaya Komunikasi terhadap Kepuasan Kerja serta dampaknya terhadap Kinerja Pegawai pada Sekretariat Daerah kota Sabang. Jurnal Ilmu Manajemen Pascasarjana Universitas Syiah Kuala, 1(2):1-17.

Sari, Elviara. 2009. Pengaruh Kompensasi dan Iklim Organisasi Terhadap Kepuasan Kerja, Bisnis dan Birokrasi. Jurnal Ilmu Administrasi dan Organisasi, 6(1):18-24.

Siagian, Sondang P. 2011. Manajemen Sumber Daya Manusia. Jakarta: Bumi Aksara.

Skansi, D. 2000. Relation of Managerial Efficiency and Leadership Style Empirical Study in Hrvatska Elektroprivreda. Journal Management, 5(2):51-67.

Sugiyono. 2013. Metode Penelitian Bisnis. Bandung: Alfabeta.

Sukarman, Kamuli. 2012. Pengaruh Iklim Organisasi Terhadap Produktivitas Kerja Pegawai di Sekretariat Daerah Kota Gorontalo. Jurnal Inovasi, 9(1)

Susanty, Etty. 2012. Pengaruh Iklim Organisasi Terhadap Kepuasan Kerja dan Komitmen Karyawan Pada Universitas Terbuka. Jurnal Organisasi dan Manajemen, 8(2):121-134.

Sutrisno, H. Edy. 2014. Manajemen Sumber Daya Manusia. Jakarta: Kencana Prenada Media Group.

Swastha, Basu. 2008. Manajemen Pemasaran Modern. Yogyakarta: Liberty.

Unika, Prihatsanti dan Kartika Sari Dewi. 2010. Hubungan Antara Iklim Organisasi dan Organizational Citizenship Behaviour Pada Guru SD Negeri di Kecamatan Mojolaban Sukoharjo. Jurnal Psikologi Undip, 7(1)

Wibisono, Anjar. 2011. Pengaruh Iklim Organisasi terhadap Kepuasan Kerja (Studi tentang Pengaruh Iklim Organisasi terhadap Kepuasan Kerja

Pegawai Puskesmas Turen di Malang). Jurnal Aplikasi Manajemen, 9(3):1000-1010.

Wirawan, Nata. 2012. Cara Mudah Memahami Statistik 2 (Statistik Infrensia) Untuk Ekonomi dan Bisnis. Edisi Ketiga. Denpasar: Keraras Emas. Wirawan. 2009. Budaya dan Iklim Organisasi. Jakarta: Salemba Empat.

Xenikou, Atena. 2006. Organisasi Culture and Transformational Leadership as Predictors of 
Business. Journal of Managerial Psychology, 21(6):566-579.

Zainal, Veithzal Rivai, Muliaman Darmansyah Hadad dan H. Mansyur Ramly. 2014. Kepemimpinan dan Perilaku Organisasi. Edisi Keempat. Jakarta: PT. Raja Grafindo Persada.

Zohar, D dan Luria, G. 2005. A Multilevel Model of Safety Climate: Cross-Level Relationships Between Organization and Group-Level Climates. Journal of Applied Psychology, 90(4):616-28. 